\title{
A RESPONSABILIDADE CIVIL NO EXERCÍCIO DA LIVRE INICIATIVA ECONÔMICA CONSTITUCIONAL NAS ORGANIZAÇÕES EMPRESARIAIS
}

\section{CIVIL LIABILITY IN THE EXERCISE OF FREE ENTERPRISE ECONOMIC BUSINESS ORGANIZATIONS IN THE CONSTITUTION}

\begin{abstract}
GIVAGo Dias MENDONÇA
Mestrando em Direito pela Cessumar. Especialista em Direito Empresarial, Direito Internacional e Economia pela UEL - Universidade Estadual de Londrina - Paraná. Professor dos cursos de Direito, Administração e Ciências Contábeis na Unifamma - União das Faculdades Metropolitanas de Maringá e na Faculdade Alvorada em Maringá. Pesquisador na área de Direito Empresarial, Direito Internacional do Comércio, Direito Econômico e Direito Contratual Mercantil.
\end{abstract}

givago@onda.com.br

\begin{abstract}
RESUMO
0 artigo científico tem por objetivo abordar o princípio constitucional da livre iniciativa econômica, garantidor da capacidade individual para o exercício da empresa, bem como os efeitos decorrentes do risco empresarial regulados pela responsabilidade civil objetiva. Com base na legislação e doutrina pertinente ao assunto foi utilizado um referencial especializado diante a construção metodológica lógica e teórica do tema apresentado.
\end{abstract}

Palavras-chave: Livre iniciativa constitucional - Teoria do risco - Responsabilidade Civil

\begin{abstract}
The research paper aims to approach the constitutional principle of free economic initiative guarantor's capacity to exercise the company as well as the effects of business risk governed by objective liability. Based on legislation and relevant teaching a specialized reference to the subject before the methodological logic and theoretical construction of the theme presented was used.
\end{abstract}

Keywords: Free constitutional initiative - Theory of Risk - Liability

\section{SUMÁRIO}

INTRODUÇÃO; 1 A LIVRE INICIATIVA CONSTITUCIONAL: PRINCÍPIO DA LIBERDADE ECONÔMICA; 2 A EMPRESA NO DIREITO BRASILEIRO; 2.1 Breve histórico; 2.2 Conceito e terminologias; 2.3 Caracterização da empresa no direito brasileiro; A TEORIA DO RISCO E A RESPONSABILISADE OBJETIVA DA EMPRESA; 3.1 Teoria do risco empresarial; 3.2 A Responsabilidade objetiva da empresa; CONCLUSÃO; REFERÊNCIAS. 


\section{INTRODUÇÃO}

As relações jurídicas são dinâmicas pelo momento histórico que a humanidade está inserida ou pela construção do livre desenvolvimento do ser humano acerca das condições e garantias da vida em sociedade. Nesse meio (sociedade) existe o ser humano com suas inúmeras diversidades individuais e valores normativos que sustentam o convívio social. Aspirar tudo isso, nos leva evidentemente à compreensão do direito, como ciência, pode tratar acerca do que é natural da ação humana e do que é domesticado pela ação coletiva, ou seja, o papel do Estado como regulador da personalidade humana em função da sociedade.

O referencial teórico desta pesquisa tramita na análise do princípio prático e presente em toda a história humana, isto é, na capacidade volitiva da busca econômica do homem. Desde a consolidação dos ideiais do pensamento libera,l o contexto econômico sempre teve a função de garantir o direito natural de qualquer indíviduo exercer sua ampla capacidade negocial.

Hoje, a liberdade econômica está positivada no modelo de predominância capitalista, adaptado ao Estado gardião da segurança jurídica, patrono da legislação em função dos direitos sociais e individuais.

O objetivo do tema visa descrever o princípio constitucional de liberdade negocial econômica (livre iniciativa) no exercício da empresa e a responsabilidade funcional das operações que decorrem da mesma, quando houver dano difuso ou coletivo em suas ações negociais. O dever de capacitar e ao mesmo tempo informar o futuro empreendedor acerca do risco econômico da atividade empresarial, tem por meta a capacitação daqueles que desejam ou estão no mercado.

A empresa como um ente dotato de personalidade no direito privado, possui atribuições importantes no desenvolvimento social. Todavia, a complexidade de relações diante a liberdade econômica não estão imunes a eventuais prejuízos motivados ou desmotivados que o exercício da atividade empresarial em detrimento da função social.

Os danos advindos da atividade econômica empresarial são domesticados no estudo da responsabilidade civil, que de forma objetiva tem por mérito impor a reparação de quaisquer prejuízos advindos na esfera negocial. Neste patamar, entra o risco negocial inerente à atividade empresarial exercida pela organização, despresando quaisquer atos subjetivos na determinação da culpa pelo modelo clássico jurídico relativo à pessoa, dando total responsabilidade ao ente empresarial. 
O trabalho está estruturado em etapas gradativas, utilizando-se da legislação de direito privado, jurisprudência e doutrina brasileira. Será descrito preliminarmente o princípio base da liberdade negocial, ou seja, o princípio da livre iniciativa economica fundada na Constituição Federal. Em seguida, será abordada a caracterização da empresa de acordo com o modelo teórico italiano adotado pela legislação nacional e, ao final, a abordagem específica da responsabilidade civil objetiva relativa ao risco econômico negocial atribuída a toda empresa no cenário econômico brasileiro.

\section{A LIVRE INICIATIVA CONSTITUCIONAL: PRINCÍPIO DA LIBERDADE ECONÔMICA}

Depois de expor os fatores preliminares do pensamento liberal e seu fundamento no direito natural e o direito da propriedade como valor inerente a vontade humana, pelos critérios albergados do jusnaturalismo, passamos agora a expor a adesão do Estado, desde a ascensão da burguesia no estabelecimento de uma classe hegemônica, ilustrado pela expressões “laissez faire e laissez passer”, onde pregava a liberdade de produção, comercialização e concorrência entre todos, tendo por base o mínimo possível de intervenção do Estado em seu mecanismo. ${ }^{1}$

Após a Revolução Industrial o liberalismo conquistou países por todo o mundo, sendo o verdadeiro propulsor da civilização moderna, ao longo do tempo o Estado passou a regular o mercado sem que atropelasse os interesses individuais e coletivos da sociedade, posto isso a nível constitucional. Mais tarde, o Estado reforçou sua composição na Segunda Revolução Industrial (1850), na Comuna de Paris (1871) e posteriormente após a Segunda Guerra Mundial (1945). ${ }^{2}$

Partindo da idéia que o Estado Liberal permite um desenvolvimento humano inestimável, e que o mesmo não possui ferramentas administrativas para funcionar sem ajuda ou mesmo ser financiado, neste momento entra em cena a livre iniciativa, da qual permite aos membros da coletividade, indivíduos em suas particularidades, a promoção em beneficio econômico próprio à aquisição de capital e propriedade, seguindo as regras condicionadas pelo Estado em seus

\footnotetext{
${ }^{1}$ CARVALHO, Leonardo Arquimimo de. Manual de direito de concorrência. São Paulo: IOB Thomson, 2005. p.15.

${ }^{2}$ CARVALHO, Leonardo Arquimimo de. Manual de direito de concorrência. São Paulo: IOB Thomson, 2005. p.16.
} 
A RESPONSABILIDADE CIVIL NO EXERCÍCIO DA LIVRE INICIATIVA CONSTITUCIONAL NAS ORGANIZAÇÕES EMPRESARIAIS

GIVAGO DIAS MENDONÇA

interesses de reversão social ${ }^{3}$. Para quem exerce a liberdade econômica é considerado como um agente.

O primeiro diploma legal a nível da livre iniciativa foi posto pelo Código Napoleônico (1804), uma inovação aos direitos de liberdade e igualdade de qualquer indivíduo em atuar no mercado, exercendo uma atividade de natureza comercial. Naturalmente que houve um choque, pois a elite burguesa tão acostumada a definir mercados em decorrência da força política e pagamento de concessão a nível local, as chamadas “guildas”, permitiam grande discricionariedade a quem queria participar do comércio. O Código Napoleônico por sua vez ilustra clareza na redação, tendo por base o iluminismo, removeu legalmente os obstáculos foram reduzidos permitindo a livre iniciativa antes condicionada. ${ }^{4}$

Nada mais, o Código Napoleônico cumpriu os ideais da Revolução Francesa no âmbito jurídico, acerca dos valores relativos à liberdade, à igualdade e à fraternidade em diversas dimensões da vida social e à pessoa humana. A livre iniciativa foi um princípio desenvolvido nestes axiomas.

Um ponto curioso é que a livre iniciativa se deriva de um ímpeto moral que vem desde o pensamento liberal originário em Jonh Locke preliminarmente. Frederick August von Hayek ${ }^{5}$ descreve muito bem tal afirmativa abaixo:

A atividade econômica nos fornece meios materiais para todos os fins. Ao mesmo tempo, grande parte dos nossos esforços individuais são destinados a fornecer aos outros, afim um retorno para os nossos próprios fins. Isso porque nós somos livres na escolha de nossos meios e somos também livres na escolha dos nossos fins.

A liberdade econômica é por consequência indispensável a todas outras liberdades e a liberdade negocial é por sua vez uma condição necessária e uma consequência da liberdade individual. ${ }^{6}$ (tradução nossa)

\footnotetext{
${ }^{3}$ BARROS, Luiz Sérgio. Livre iniciativa: um caminho para o desenvolvimento. vol.5. - Brasília: Coleção Brasil, 1998. p.10-11.

${ }^{4}$ SCHIEMANN, Georg; BARTLMAE, Elmar. Sob o domínio de Napoleão - parte 1 [Filme-video]. BIEHOUNEK, Ulrike (Coord.). Life under Napoleon. Alemanha, MDR/WDR/LOOKS Coorporation, 2006. Web-video, 52:53 min. Som stereo. Disponível em: <http://www.youtube.com/watch?v=BFMngo-dtEk>. Acesso em: 15 ago. 2012.

5 HAYEK, Frederick A. Von. La composante moral da la libre entreprise. Disponível em: <http://www.dantou.fr/Economie.html. Acesso em: 15 ago. 2012.

${ }^{6}$ L'activité économique nous fournit les moyens matériels de toutes nos fins. Dans le même temps, la plupart de nos efforts individuels sont destinés à fournir à d'autres des moyens en vue de leurs fins afin qu'ils nous fournissent en retour les moyens en vue de nos fins. C'est uniquement parce que nous sommes libres dans le choix de nos moyens que nous sommes aussi libres dans le choix de nos fins.

La liberté économique est par conséquent une condition indispensable de toute autre liberté, et la libre entreprise est à la fois une condition nécessaire et une conséquence de la liberté individuelle.
} 
Considerando o desenvolvimento econômico e pormenorizando os termos também aderidos pela Constituição Brasileira, nos arts. 1, IV e 170, II e IV ${ }^{7}$, a livre iniciativa pode ser definida como valor decorrente da liberdade dos privados de dispor dos recursos materiais e humanos na propriedade e na competitividade, sendo em segundo lugar o direito de organização da atividade produtiva, e, consequentemente o direito de decisão o que produzir, quando produzir, como produzir e onde produzir. ${ }^{8}$

A partir deste fundamento estaríamos se submetendo ao Estado no papel de legitimador constitucional da legislação para o aperfeiçoamento compulsório dos atos privados do processo econômico, isto é, considera-se a livre iniciativa como uma atividade econômica privada acerca do exercício, desde que não suprima a possibilidade de autodeterminação direta e indireta do indivíduo em sua manifestação. ${ }^{9}$

A função do Estado na livre iniciativa deve ser pautada na atuação com justiça na sociedade econômica, evitando violência e corrigir aquelas atitudes antissociais que lesam indivíduos $^{10}$. A repreensão e o não incentivo a determinados casos evitam levar os agentes operantes no mercado, tais como trabalhadores, fornecedores, consumidores ao perfil miserável a quem tem por titularidade a produção e circulação de bens e serviços, prejudicando o sistema social.

Para Adam Smith, grande filósofo exponente da ciência econômica em diversas obras ainda aplicadas na prática mercadológica, por mais contra que foi a toda e qualquer intervenção estatal no exercício da livre iniciativa no século XVIII, merece salientar a sua preocupação com sociedade e a felicidade quando seus membros fossem pobres e miseráveis, levando uma vida irregular, incerta e cheia aventuras arriscadas. ${ }^{11}$ Assim, já após o século XIX em diante foi inconcebível delegar apenas ao mercado as condições vitais do exercício da livre iniciativa, entrando em cena o Estado como principal e único ente que poderia valer e corrigir quaisquer atos de arbitrariedades ou atrocidades levados pela ambição natural do lucro do ser humano.

\footnotetext{
7 BRASIL. Constituição (1988). Constituição da República Federativa do Brasil: promulgada em 5 de outubro de 1988. Contém as emendas constitucionais posteriores. Brasília, DF: Senado, 1988.

${ }^{8}$ RIOS, Roger Raupp. Ordem econômica, sociabilidade e os mass media na constituição da república de 1988. Justiça do Direito - UPF, Passo Fundo. v.9, n.9. 1996. p.204.

${ }^{9}$ RIOS, Roger Raupp. Ordem econômica, sociabilidade e os mass media na constituição da república de 1988. Justiça do Direito - UPF, Passo Fundo. v.9, n.9. 1996. p.205-206.

${ }^{10}$ SAKAMOTO, Bernardo Alfredo Mayta. Da ordem astronômica à ordem social: a gravitação e o indivíduo como fundamentos do Mercado. Cascavel: Edunioeste, 2010. p.97.

11 SAKAMOTO, Bernardo Alfredo Mayta. Da ordem astronômica à ordem social: a gravitação e o indivíduo como fundamentos do Mercado. Cascavel: Edunioeste, 2010. p.98-99.
} 
A assertiva moderna do tratamento deste princípio se recolhe hoje a valores fundamentais constitucionais em relação a autonomia da vontade em sentido amplo diante a natureza humana, como bem elucida Celso Ribeiro Bastos em lições valiosas acerca deste princípio :

[...] a livre iniciativa é uma expressão fundamental da concepção liberal do homem, que coloca como centro a individualidade de cada um. Para o liberal, a livre iniciativa é necessária para a sua própria expressão e dignidade enquanto homem, porque cabe-lhe imprimir um destino a sua vida, uma escolha, a expressão da sua capacidade, e isso tudo só é conseguido através da liberdade que se reserva a cada um para poder exercer a atividade econômica. ${ }^{12}$

O exercício da livre iniciativa econômica decorre do exercício dos direitos da personalidade. Estes foram galgados historicamente com advento dos direitos da primeira e segunda geração/dimensão no que tange o conteúdo das liberdades individuais e sociais, perceptíveis a partir de meados do século XIX. A primeira geração/dimensão (direitos civis e políticos) acerca do indivíduo tratados no conteúdo negativo da liberdade e a segunda geração (direitos econômicos, sociais e culturais) em relação do indivíduo como ente social em conteúdo positivo da liberdade. ${ }^{13}$

O princípio da livre iniciativa se comporta amplamente conteúdo negativo, desconsiderando os critérios positivos pregados pelo Estado Social em análise. Contudo, devemos nos ater que os direitos da personalidade, seja no aspecto das liberdades positivas e negativas, estão diretamente envolvidos ao espírito humano diante suas inúmeras complexidades acerca de um fundamento, o princípio da dignidade, como bem define Ingo Wolfgang Sarlet:

[...] "a qualidade intrínseca e distintiva reconhecida em cada ser humano que o faz merecedor do mesmo respeito e consideração por parte do Estado e da comunidade, implicando, neste sentido, um complexo de direitos e deveres fundamentais que assegurem a pessoa tanto contra todo e qualquer ato de cunho degradante e desumano, como venham the garantir as condições existenciais mínimas para uma vida saudável, além de propiciar e promover sua participação ativa e corresponsável nos destinos da própria existência e da vida em comunhão

\footnotetext{
12 BASTOS, Celso R. apud CARVALHO, Leonardo Arquimimo de. Manual de direito de concorrência. São Paulo: IOB Thomson, 2005. p.66.

${ }^{13}$ RIOS, Roger Raupp. Ordem econômica, sociabilidade e os mass media na constituição da república de 1988. Revista Justiça do Direito - UPF, Passo Fundo, v.9, n.9. 1996. p.211.
} 
com os demais seres humanos, mediante o devido respeito aos demais seres que integram a rede da vida." 14

Partindo desta conjectura, Sarlet também defende o grau dimensional da dignidade, apontando um duplo grau do conteúdo negativo, constante a manifestação da pessoa humana em sua autodeterminação nas decisões da sua própria existência, e a necessidade de proteção e assistência da comunidade e o Estado na viabilidade da manifestação privada. ${ }^{15}$

Nesse ponto Sarlet esclarece o que intitula de "dimensão autonômica”, acerca da própria decisão pessoal em função da dignidade. O exercício da liberdade negocial para fins econômicos parte dessa perspectiva e não pode ser dissociado da razão prática da personalidade humana em razão a si mesmo (fator individual), ressalvado os valores coletivos determinados pela ordem pública.

\section{A EMPRESA NO DIREITO BRASILEIRO}

\subsection{Breve histórico}

Desde os primórdios do homem até a Antiguidade, o fato gerador do comércio se fundia na troca natural de coisas e objetos (prática de escambo), pois as necessidades individuais e sociais eram crescentes desde que se têm dados acerca da idade da pedra polida, tornando-se uma das razões para qualquer ser humano viver em coletividade. A partir das trocas de bens, 0 exercício da liberdade humana evoluiu para fase pecuniária, com a criação da moeda ${ }^{16}$.

Os fenícios, civilização desenvolvida por atuar no âmbito da navegação, foram os primeiros de que se tem notícia, uma cultura fundada na liberdade subjetiva de comércio, a qual foi tomada pelas civilizações Assírias, Gregas e povos da Ásia. O Código de Hamurábi elenca - mesmo que implicitamente - em seus artigos algumas referências acerca da liberdade da atividade comercial na Babilônia; contudo, há doutrinadores que sustentam a posição de não haver nenhuma ligação. Aos árabes podemos atribuir os primeiros indícios do pensamento liberal

\footnotetext{
${ }^{14}$ SARLET, Ingo Wolfang. Dignidade da pessoa humana e direitos fundamentais na Constituição Federal de 1988. 7. ed. rev. atual. Porto Alegre: Livraria do Advogado, 2009. p.67.

${ }^{15}$ SARLET, Ingo Wolfgang. As dimensões da dignidade humana: construindo uma compreensão jurídicoconstitucional necessária e possível. In: Dimensões da dignidade: ensaios de filosofia do direito e direito constitucional. 2. ed. Porto Alegre: Livraria do Advogado, 2009, p.30.

${ }^{16}$ BULGARELLI, Waldirio. Direito comercial. 15. ed. São Paulo: Atlas, 2002. p.26-27.
} 
arcaico, após o século $\mathrm{V}$, com o rompimento da pax romana ${ }^{17}$, quando assumiram um papel preponderante do exercício do direito à barganha como filosofia de vida para a realização humana e das práticas mercantis. ${ }^{18}$

Apesar da dificuldade do homem de alcançar sua liberdade pessoal e mercantil, com o monopólio dos barões feudais, surgiram as chamadas cidades burguesas. Essas tiveram como denominação de terceiro Estado, por conceber a qualquer individuo que ali habitava o sentimento de liberdade. 0 direito de mercado predominava nestas cidades como o destino da produção no comércio, aliada às Corporações de Ofício. As corporações de Ofício era uma classe elitizada e organizada dos mercadores, obtiveram grande sucesso e poderes políticos. ${ }^{19}$

A idéia do lucro à pessoa que exercia a atividade comercial pelo seu trabalho, era ainda considerada intolerável perante os dogmas da Igreja, ou seja, a barganha era um pecado do comerciante que comprava para vender mais caro. Mesmo assim, conquistaram através do caráter subjetivo individual a autonomia para alguns centros comerciais, por exemplo, as poderosas cidades italianas de Veneza, Florença, Gênova, Amalfi e outras. ${ }^{20}$

A Revolução Francesa (1789) marcou o período moderno do comércio com seus princípios baseados na igualdade, solidariedade e fraternidade, resultando no Código Civil e Comercial Francês. O Code de Commerce napoleônico, datado em 1807, marcou o abandono do subjetivismo corporativista ${ }^{21}$. Com a implantação da objetividade dos atos legais de comércio inicia-se a fase objetiva a partir deste corpo legislativo positivo. ${ }^{22}$

Mais tarde, com o advento da Segunda Revolução Industrial, projetou-se a atividade mercantil em larga escala, voltada para atender as necessidades humanas, marcando assim o desenvolvimento tecnológico com a adoção de novas fontes de energia e máquinas no processo produtivo. $^{23}$

A atual fase do Direito Comercial provém do Códice Civile Italiano de 1942, justificada pelo setor econômico na gestão de negócios. A empresa é o objeto do direito comercial

\footnotetext{
17 Período de relativa paz no Império Romano, datado entre 28 a.C. e 180 d.C., foi um período de progresso científico e de desenvolvimento humano dos povos conquistados por Roma.

${ }^{18}$ BULGARELLI, Waldirio. Direito comercial. 15. ed. São Paulo: Atlas, 2002. p.28.

19 PACKER, Amilcar Douglas. Direito comercial - origem e evolução. 1. vol. Curitiba: Juruá, 2002. p.30-34.

${ }^{20}$ REQUIÃO, Rubens. Curso de direito comercial. 25. ed. 1. vol. São Paulo: Saraiva, 2003. p.9-10.

${ }^{21} \mathrm{O}$ comércio era exercido tão apenas pelo seu titular proprietário, ou mesmo com a ajuda de alguns raros auxiliares ou trabalhadores

${ }^{22}$ FAZZIO JÚNIOR, Waldo. Manual de direito comercial. 5. ed. São Paulo: Atlas, 2005. p.30.

${ }^{23}$ PACKER, Amilcar Douglas. Direito comercial - origem e evolução. 1. vol. Curitiba: Juruá, 2002. p.38-39.
} 
moderno, com base na organização dos fatores de produção, ou seja, hoje quem exerce 0 comércio são as organizações empresárias. ${ }^{24}$

\subsection{Conceitos e terminologias}

Dentre os diversos conceitos tomados na doutrina da matéria do direito comercial, tais definições não permitem satisfazer o seu objeto, vista que não correspondem integralmente e amplitude da disciplina. Assim, citamos alguns conceitos mais difundidos na matéria, conforme o sentido material do conteúdo jurídico do direito comercial.

Para Vivante, o direito comercial "é a parte do direito privado que tem principalmente por objeto regular as relações jurídicas que surgem do exercício do comércio". ${ }^{25}$

Lyon-Caen et Renalt descreveram "o direito comercial propriamente dito tem por fim regular relações entre particulares a que dá lugar ao exercício do comercio". ${ }^{26}$ Cosack entendeu que "o direito mercantil compreende todas as regras do direito privado que de modo especial se adaptam às necessidades ou exigências do trafico comercial". ${ }^{27}$ No mesmo sentido, Rocco definiu o direito comercial como "o direito do comércio, ou seja, o complexo das normas jurídicas que regulam as relações derivadas da indústria comercial”. ${ }^{28}$

Por outro lado, exprimindo as bases da análise do comércio para o consumo, Ripert conceituou como "a parte do direito privado que regula as operações jurídicas feitas pelos comerciantes, seja entre si, seja entre os seus clientes". ${ }^{29}$

$\mathrm{Na}$ tentativa de chegar a uma definição mais exata do âmbito do direito comercial Waldemar Ferreira sintetizou ao declarar que o direito comercial é "o conjunto sistemático de normas jurídicas disciplinadoras do comerciante e seus auxiliares e do ato de comércio e das relações dele oriundas". ${ }^{30}$ Ainda, no mesmo sentido, Carvalho de Mendonça esclarece que “o direito comercial é a disciplina jurídica reguladora dos atos de comércio e, ao mesmo tempo, dos direitos e das obrigações das pessoas que exercem profissionalmente e dos seus auxiliares". ${ }^{31}$

\footnotetext{
${ }^{24}$ BULGARELLI, Waldirio. Direito comercial. 16. Ed.São Paulo: Atlas, 2001. p.15-20.

${ }^{25}$ VIVANTE apud MARTINS, Fran. Curso de direito comercial. 27. ed. Rio de Janeiro: Forense, 2001. p.14.

${ }^{26}$ LYON-CAEN E RENALT apud MARTINS, Fran. Idem nota 25. p.14.

${ }^{27}$ COSACK apud MARTINS, Fran. Idem nota 25. p.14.

${ }^{28}$ ROCCO apud MARTINS, Fran. Idem nota 25. p.15.

${ }^{29}$ RIPERT apud MARTINS, Fran. Idem nota 25. p.15.

${ }^{30}$ FERREIRA apud MARTINS, Fran. Idem nota 25. p.15.

${ }^{31}$ MENDONÇA apud MARTINS, Fran. Idem nota 25. p.15.
} 
Por fim, Fran Martins subtraindo dos conceitos de Ripert, Waldemar Ferreira e Carvalho de Mendonça, conceitua o direito comercial como "o conjunto de regras jurídicas que regulam as atividades das empresas e dos empresários comerciais, bem como os atos considerados comerciais, mesmo que esses atos não se relacionem com as atividades das empresas". ${ }^{32}$

De todas as definições citadas devemos nos ater que os conceitos taxativos são perigosos, podendo ser até equivocados diante a matéria comercial em sua realidade jurídica, contudo deve ser logo considerado que o direito comercial apropriou-se do ora chamado na atualidade dos fatores econômicos por meio unicamente da empresa, e ainda com o advento do Código Civil Brasileiro de 2002, a falsa unificação do direito privado em tese antes formalizada pela sua dicotomia, partiu-se para o modelo do Código Civil Italiano que "fundou-se simplesmente na figura do empresário ou sociedade empresária com finalidade de lucro e a assunção dos respectivos riscos". 33

A partir das informações contidas no desenvolver histórico do direito comercial e os conceitos, existe uma certa dificuldade de se compreender qual a diferença dos termos ora difundidos na literatura pela respectiva denominação de direito comercial, direito mercantil (denominado por alguns doutrinadores) e direito empresarial. A certeza nessa questão é que tais terminologias foram usadas em diferentes momentos históricos conforme a evolução dos costumes e a legislação. Desta forma, os termos foram utilizados como atributo de evolução das práticas comerciais relativas às simples trocas (escambo) para as organizações empresariais hoje existentes.

Diante disso, as três terminologias direito comercial, direito mercantil e direito empresarial são usualmente empregadas pela doutrina especializada para diferenciar e fazer a atribuição dos momentos históricos. Em muitos casos, causa-nos confusão na compreensão destas terminologias, vista que na academia cientifica os componentes curriculares obrigatórios e eletivos possuem material bibliográfico de produção variada, dais quais são utilizadas. Assim, para uma melhor compreensão e aprendizado atual, vamos colocar aqui tais denominações (direito comercial, direito mercantil e direito empresarial) como expressões sinônimas para a compreensão do ramo jurídico.

32 FRAN, Martins. Curso de direito comercial. 27. ed. Rio de Janeiro: Forense, 2001. p. 16.

${ }^{33}$ FAZZIO JÚNIOR, Waldo. Manual de Direito Comercial. 5. ed. São Paulo: Atlas, 2005, p.36. 


\subsection{Caracterização da empresa no direito brasileiro}

Em relação a organização econômica qualificada e denominada como empresa, o direito brasileiro infelizmente não a definiu as características jurídicas possíveis de sua terminologia ou significação. Todavia, a doutrina italiana seguida pelo ordenamento brasileiro desde a promulgação e publicação do Código Civil Brasileiro no ano de 2002, adotou a teoria da empresa mudando profundamente a compreensão e a noção jurídica dessas organizações constituídas no país, antes tomadas pela doutrina francesa dos atos de comércio adotadas anteriormente pelo Código Comercial Brasileiro (1850), hoje revogado na sua parte geral.

Para melhor compreensão, o significado da palavra empresa conforme a sua forma gramatical e lexica tem suas origens na língua italiana IMPRESA e se refere à "atividade a que uma pessoa se dedica ou conduz", como do latim EMPREHENDERE, formado por EM-, “em”, mais PREHENDERE, que significa "pegar, capturar, levar diante de si, segurar". No Brasil, o sentido linguístico é mais empregado como substantivo ${ }^{34}$ definido relativo a um determinado complexo de bens materiais, uma associação comercial restrita a um local onde exerce determinada econômica, o ponto comercial ou estabelecimento comercial onde gera os negócios. Tal sentido é totalmente equivocado e pode gerar confusões imprecisas, pois as legislações atuais de direito empresarial, de direito internacional do comércio e de direito comparado definem o significado da palavra conforme a língua italiana e o latim, mais precisamente como uma ação humana referente "ao exercício e a condução de atividade econômica organizada".

A teoria da empresa de 1942, criada pelo italiano Alberto Asquini, determinou o sentido da empresa como o ato ou exercício, atividade econômica organizada. Apesar de ser definido juridicamente o termo "empresa”, no art. 2.082 do Código Civil Italiano dirige implitamente o conceito em função da pessoa do empresário, qualficando quem exerce profissionalmente uma atividade econômica organizada afim de produzir e circular bens ou serviços. ${ }^{35}$

Alberto Asquini, contribuindo na formação e criação legislativa da teoria da empresa no direito italiano, justificou a construção normativa em quatro perfis/elementos para caracterização da empresa, no sentido de atividade econômica organizada.

0 primeiro perfil/elemento, está ligado ao aspecto subjetivo de quem exerce a empresa, ou seja, o empresário; o segundo perfil/elemento em seu aspecto funcional ou dinâmico,

\footnotetext{
${ }^{34}$ FERNANDES, Francisco. LUFT, Celso Pedro. GUIMARÃES, F. Marques. Dicionário brasileiro globo. 21. ed. São Paulo: Globo, 1991.

${ }^{35}$ FAZZIO JÚNIOR, Waldo. Manual de Direito Comercial. 5. ed. São Paulo: Atlas, 2005, p.36.
} 
baseada na atividade empresarial dirigida para um determinado escopo produtivo; o terceiro perfil/elemento de aspecto objetivo e patrimonial, dirigida ao exercício da atividade empresarial em seu determinado fim (atividade lucrativa) e o complexo de bens móveis ou imóveis, corpóreos e incorpóreos utilizadas pelo mesmo; por fim no quarto perfil/elemento, temos o corporativo ou institucional, onde a empresa é vista como resultado da organização pessoal, formada pelo empresário e por seu colaboradores (dirigentes, funcionários, operários etc.). ${ }^{36}$

\section{A TEORIA DO RISCO E A RESPONSABILIDADE OBJETIVA}

\subsection{Teoria do risco empresarial}

A teoria do risco empresarial provém da caracterização da responsabilidade civil. Historicamente a responsabilidade civil foi concebida inicialmente no âmbito estritamente privado, da qual o legislador atribui a iniciativa particular na reparação do dano, exercido pelo direito da vingança. Mais tarde, tal atribuição passou ao Estado nos tempos da república romana pela Lex Aquila, da qual destaca Caio Mário da Silva Pereira:

[...] a maior revolução nos conceitos jus-romanísticos em termos da responsabilidade civil é a Lex Aquilia, de data incerta, mas que se prende aos tempos da República. Tão grande a revolução que ela se prende a denominação de aquiliana para designar-se a responsabilidade extracontratual em oposição à contratual. Foi um marco tão acentuado, que a ela se atribui a origem do elemento "culpa", como fundamental na reparação do ano. A Lex Aquilia, bem assim a consequente actio ex lege Aquilia, tem sido destacada pelos romanistas e pelos civilistas, em matéria atinente à responsabilidade civil. ${ }^{37}$

A partir deste momento não se tinha a plena convicção da responsabilidade objetiva, tão apenas por entender que a culpa era atribuída pela simples concepção subjetiva em decorrência da lei ou do contrato. Mais tarde, a evolução da matéria nas legislações culminaram o aperfeiçoamento direito do conteúdo, da qual no Código Civil Brasileiro adota como uma regra geral nos arts. 186 e 187. Ainda, embora muito adstrito a responsabilidade objetiva, o art.187

\footnotetext{
${ }^{36}$ NEGRÃO, Ricardo. Manual de direito comercial e a de empresa. v. 1. 3. ed. São Paulo: Saraiva, 2003. p.41-44.

${ }^{37}$ PEREIRA, Caio Mário da Silva. Responsabilidade Civil. Rio de Janeiro: Forense, 1990, p.8.
} 
A RESPONSABILIDADE CIVIL NO EXERCÍCIO DA LIVRE INICIATIVA CONSTITUCIONAL NAS ORGANIZAÇÕES EMPRESARIAIS

GIVAGO DIAS MENDONÇA

trata do abuso de direito que excede os fins econômicos e sociais e a devida responsabilização por ato ilícito. ${ }^{38}$

Não obstante, devemos levar em consideração que ao falar em responsabilidade civil objetiva, deve-se refutar a regra subjetiva da responsabilização, e assim tecer seu fundamento das correntes doutrinárias fundamentais que caracterizem o desenvolvimento no que tange à reparação dos danos advindos ou cometidos pelas organizações empresarias em especial, isto é, a compreensão da Teoria do Risco.

A Teoria do Risco é um embasamento jurídico elaborado por diversos doutrinadores no final do século XIX para justificar a responsabilidade objetiva, da qual semântica se refere a acepção jurídica de perigo, potencialidade de dano, previsibilidade de perda ou de responsabilidade pelo dano incerto e futuro inesperados que possa trazer ou alocar possíveis perdas e danos. ${ }^{39}$

Dentre inúmeras teorias acerca do risco podemos destacar em relação ao conteúdo vinculado as organizações empresariais algumas do ponto de vista fundamental que vai traduzir a responsabilização objetiva, a modalidade do risco-profissional, o risco-proveito, o risco do desenvolvimento e o risco do empreendimento.

Derivada excepcionalmente do fato que possa vir a decorrer no exercício de uma atividade profissional, neste caso considera-se a pessoa do empresário (pessoa física) como titular da organização, responsável pela capacidade produtiva do objeto econômico diante aos diversos atos operacionais da gestão ${ }^{40}$. A lei é consistente quando define jurídicamente o que é empresário no direito das empresas, conforme o art. 966, caput do Código Civil Brasileiro: "Considera-se empresário quem exerce profissionalmente atividade econômica organizada para a produção ou a circulação de bens ou servicos". ${ }^{41}$

Nesse sentido, o Estado foca seu dever já enunciado pela Contituição Federal em seus princípios econômicos da livre iniciativa e a livre concorrencia fundados no art. 170 e seguintes, atribuindo proteção ao empresário suas atividades, tratando a empresa como agente econômico, bem como à sua organização diante a propriedade coorporativa mercantil. Assim, qualquer

\footnotetext{
${ }^{38}$ BRASIL Lei $n^{\circ} 10.406$, de 10 de janeiro de 2002. Código Civil Brasileiro. Legislação Federal. Disponível em: <http://www.planalto.gov.br/ccivil_03/leis/2002/L10406compilada.htm>. Acesso em: 16 dez.2012.

39 WOLKOFF, Alexander Porto Marinho. A teoria do risco e a responsabilidade civil objetiva do empreendedor. Disponível em: < http://www.tjrj.jus.br/c/document_library/get_file?uuid=ae2e5cc8fa16-4af2-a11f-c79a97cc881d\&groupld=10136> Acesso em: 16 dez. 2012.

${ }^{40}$ Idem nota 39.

${ }^{41}$ BRASIL Lei ${ }^{\circ} 10.406$, de 10 de janeiro de 2002. Código Civil Brasileiro. Legislação Federal. Disponível em: <http://www.planalto.gov.br/ccivil_03/leis/2002/L10406compilada.htm>. Acesso em: 16 dez.2012.
} 
gestão empresarial condutora de todas relações negociais dentro da empresa fica sujeita a regulação de diversos atos de administração em leis empresariais.

Waldírio Bulgarelli, doutrinador de direito comercial, sempre afirmou como outros autores, que a empresa é uma atividade econômica organizada, onde o empresário a exerce profissionalmente dentro do seu estabelecimento ${ }^{42}$.

No exercício da profissão de empresário ou preposto (profissionais de outras áreas considerados colaboradores do empresário) é onde que se encontra as práticas da gestão empresarial reguladas em lei para os negócios habituais da empresa, dos quais não abandonam a caracterização do risco econômico da atividade relativo às expectivas dos resultados (lucro) ou nas ações que possam ocorrer a terceiros ou a estrutura corporativa do exercício da atividade empresarial.

Se tratando do risco proveito, é avaliado pelo lucro econômico abusivo e aludido ao enriquecimento ilícito como prova inequívoca do excesso da livre iniciativa como bem dispõe os arts. 884 a 886 do Código Civil Brasileiro. ${ }^{43}$

Embora outras questões podem ser alocadas ao risco proveito, esta concepção também residem todos os atos e fatos que possam advir das práticas infrativas econômicas frente 0 direito de concorrência. Com o exercício da livre iniciativa, a lei 12.529/2011, torna como proposta normativa regulamentadora do art. 170, IV da Constituição Federal. 0 princípio da livre concorrência foi devidamente colocado em evidencia, pois fundamenta os aspectos da responsabilidade objetiva no ordenamento antitruste brasileiro, onde aloca as regras de condutas anti-concorrenciais gerais e especiais (arts. 36 e 37), bem como as penas a ser impostas e o controle das estruturas de gestão na concorrência e na propriedade industrial.

De outro lado existe o risco do desenvolvimento, do qual Marcelo Junqueira Calixto conceitua de forma prática e consistente como:

Aqueles riscos não cognoscíveis pelos mais avançados estados da ciência e da técnica no momento da introdução do produto no mercado de consumo e que só vêm a ser descobertos após um período de uso do produto em decorrência do avanço dos estudos científicos. ${ }^{44}$

\footnotetext{
${ }^{42}$ BULGARELLI, Waldirio. Sociedades comerciais. 8. Ed. - São Paulo: Atlas, 1999.p.298.

${ }^{43}$ BRASIL Lei $n^{\circ} 10.406$, de 10 de janeiro de 2002. Código Civil Brasileiro. Legislação Federal. Disponível em: <http://www.planalto.gov.br/ccivil_03/leis/2002/L10406compilada.htm>. Acesso em: 16 dez.2012.

${ }^{44}$ CALIXTO, Marcelo Junqueira. A responsabilidade civil do fornecedor de produtos pelos riscos do desenvolvimento. Rio de Janeiro: Renovar, 2004. p.176.
} 
O risco do desenvolvimento está ligado a idéia do perigo ainda desconhecido na aplicação técnica e cientifica de um produto ou serviço colocado no mercado, e porventura, poderá trazer efeitos nocivos diretos e indiretos as pessoas. Nesta concepção reside os danos ambientais provenientes pela produção de produtos nocivos e ao impacto na natureza e os danos à saúde humana dos consumidores.

O Código Civil Brasileiro ${ }^{45}$, no art. 931, expõe o fundamento ao risco do desenvolvimento diante o empresário individual na circulação de produtos, contudo tal questão é interpretada extensivamente pela doutrina, colocando não só a pessoa do empresário, mas também a empresa e seu complexo organizacional ${ }^{46}$.

Por fim, existe o chamado risco do empreendimento, do qual está ligado a idéia de que a responsabilidade da organização, independentemente aos atos praticados subjetivamente pelos componentes coorporativos, assumem sempre uma situação de risco devido estar inserido no meio econômico é passível a probabilidade de insucesso, seja com ou sem a culpa. ${ }^{47}$

Como bem comenta a respeito, Sérgio Cavalieri afirma que o risco do empreendimento é imanente ao dever da obediência legislativa, juntamente com os critérios éticos prestados pela organização ao público nos serviços e bens produzidos ou circulados ${ }^{48}$. A reponsabilidade reside sempre na qualidade e segurança perante a ordem pública, referente a toda gama de relacionamento negocial da atividade empresarial, ou seja, pelos fornecedores, trabalhadores, consumidores, meio ambiente etc.

\subsection{A responsabilidade objetiva da empresa}

Com base no exposto até o momento descrito, o exercício da livre iniciativa e a responsabilidade advinda pelo exercício da atividade empresarial, atualmente construído pelas organizações, é fruto desenvolvimento industrial e a mecanização da produção em massa. No

\footnotetext{
${ }^{45}$ BRASIL Lei no 10.406, de 10 de janeiro de 2002. Código Civil Brasileiro. Legislação Federal. Disponível em: <http://www.planalto.gov.br/ccivil_03/leis/2002/L10406compilada.htm>. Acesso em: 16 dez.2012.

${ }^{46}$ AFONSO, Humberto Manoel. A responsabilidade empresarial no código civil. 0 art. 931, seu conteúdo e alcance. Revista Jurídica: órgão nacional da doutrina, jurisprudência, legislação e crítica judiciária. Ano 52, n.321, Porto Alegre, jul. 2004. p.77.

47 WOLKOFF, Alexander Porto Marinho. A teoria do risco e a responsabilidade civil objetiva do empreendedor. Disponível em: < http://www.tjrj.jus.br/c/document_library/get_file?uuid=ae2e5cc8fa16-4af2-a11f-c79a97cc881d\&groupld=10136> Acesso em: 16 dez. 2012.

${ }^{48}$ CARVALIERI FILHO, Sérgio. Programa de responsabilidade civil. 7. ed. São Paulo: Atlas, 2007. p.162164.
} 
final do século XIX, os juristas Raymond Saleilles e Louis Josserand ${ }^{49}$, buscaram um fundamento para a responsabilidade objetiva pela teoria do risco, onde bem salienta Maria Helena Diniz apoiado nesses juristas:

A responsabilidade objetiva funda-se num princípio de equidade, existente desde o direito romano: aquele que lucra com uma situação deve responder pelo risco ou pelas desvantagens dela resultantes (ubi emolumentum, ibi ônus, ubi commoda, ibi incommoda). ${ }^{50}$

Savatier elaborou uma definição precisa sobre a responsabilidade objetiva fundada no risco em detrimento da responsabilidade, da qual coloca a obrigação de indenizar o dano produzido por atividade exercida no interesse do agente e sob seu controle, sem que haja nenhuma indignação sobre o comportamento do lesante, fundamentada na relação de causalidade entre o nexo do dano com a conduta do causador. ${ }^{51}$

A responsabilização objetiva, não importa a culpa e sim como bem já salientado pelo nexo de causalidade entre o agente e o dano causado. Sendo que, referente ao exercício de qualquer atividade econômica está vinculada obrigatoriamente ao risco criado da responsabilidade extracontratual ampla e irrestrita como preconiza o art. 927, parágrafo único do Código Civil:

Art. 927. Aquele que, por ato ilícito, causar dano a outrem, fica obrigado a repará-lo.

Parágrafo único. Haverá obrigação de reparar o dano, independentemente de culpa, nos casos especificados em lei, ou quando a atividade normalmente desenvolvida pelo autor do dano implicar, por sua natureza, risco para os direitos de outrem.

Embora haja inúmeros doutrinadores que questionam o sentido do parágrafo único deste artigo, deve-se entender que é uma norma juridicamente indefinida, devendo ser disposta conforme a realidade social e os valores substabelecidos no momento histórico do ponto de vista do risco em relação a atividade proporcionada na sociedade. No nosso caso, todo e qualquer exercício de atividade econômica.

\footnotetext{
${ }^{49}$ SALIM, Adib Pereira Netto. A teoria do risco criado e a responsabilidade objetiva do empregador em acidentes de trabalho. Revista do Tribunal Regional do Trabalho $3^{\text {a }}$ Região, Belo Horizonte, v.41, n.71, jan./jun.2005. p.102.

${ }_{50}$ DINIZ, Maria Helena. Curso de direito civil brasileiro. v.7. São Paulo: Editora Saraiva, 2004. p.48.

${ }^{51}$ Idem nota 49. p.103.
} 
O Enunciado 38 da Jornada de Direito Civil promovida pelo Centro de Estudos do Conselho da Justiça Federal, ocorrido em Brasília no mês de setembro de 2002, definiu um entendimento peculiar ao art. 927, parágrafo único do Código Civil, nos seguintes termos:

A responsabilidade fundada no risco da atividade, como prevista na segunda parte do parágrafo único do art. 927 do Código Civil, configura-se quando a atividade desenvolvida pelo autor do dano causar à pessoa determinada um ônus maior do que os demais membros da coletividade. ${ }^{52}$

Com base nesse entendimento, foi determinado que a responsabilidade objetiva decorrente de qualquer atividade decorre da evidencia do dano, a aplicação racional do princípio da proporcionalidade e razoabilidade das relações devem estar aliados na medida e determinação da indenização a partir dos valores da realidade social e não meramente ao valor subjetivo da pessoa lesada. No tocante a atividade empresarial promovida pelas organizações, parece cabível e plausível o enunciado quando do exercício da livre iniciativa, diante o prospecto e os riscos negociais da profissão de empresário, do critério fim do lucro, do desenvolvimento na circulação de bens e serviços e o risco do empreendimento.

A excludente e atenuante da responsabilidade objetiva é meramente tomada quando o nexo causal não for configurado ou houver uma culpa concorrente do lesado ao fato ocorrido ${ }^{53}$. Embora muito incomum e geralmente desenvolvida pela jurisprudência essa questão, o risco objetivo de quaisquer atividade ainda se pauta pelos critérios ou princípios da fragilidade da pessoa que sofreu o dano (hipossuficiência presumida) nas relações jurídicas.

\section{CONCLUSÃO}

Diante o referencial teórico apresentado, conclui-se que o exercício da livre iniciativa econômica está vinculado ao exercício da capacidade individual (subjetividade) em razão dos atributos da personalidade. 0 direito de liberdade de agir ou não em determinado complexo

\footnotetext{
${ }^{52}$ SALIM, Adib Pereira Netto. A teoria do risco criado e a responsabilidade objetiva do empregador em acidentes de trabalho. Revista do Tribunal Regional do Trabalho $3^{\text {a }}$ Região, Belo Horizonte, v.41, n.71, jan./jun.2005. p.107.

${ }^{53}$ Idem nota 52. p.109.
} 
organizacional para circulação ou produção de bens e serviços determina o exercício da empresa em detrimento da função social e a o papel do Estado na economia de mercado.

O exercício profissional na constituição da organização empresarial está fundada nos critérios de liberdade de trabalho em razão do ímpeto humano econômico, isto é, decorre de uma autorização de ordem pública e, ao mesmo tempo, a garantia da dignidade humana conforme as ambições econômicas que não contradizem a lei.

Os direitos da personalidade atua como elemento originário do exercício da livre iniciativa, tutela o individuo em todos os atos da vida negocial privada, diante a capacidade de angariar resultados econômicos e lucrativos nos moldes sociais, contudo em benefício particular em relação a dignidade subjetiva.

O estudo histórico do direito empresarial nos faz refletir sobre o desenvolvimento do próprio comércio, em um sentido amplo e exato, avaliando as graduações e, permitindo na atualidade utilização do um método reflexivo e crítico, que haja em favor da evolução das ciências mercadológicas.

O conceito jurídico de direito empresarial é incompleto e imperfeito, pois no processo histórico da atividade econômica mercantil, os modelos evolutivos passados, até o fenômeno atual das organizações, não precisa de um conceito acabado, mas sim de argumentos e critérios que resumem as diversas finalidades do direito empresarial e das relações sociais de mercado.

A regra de Asquini, do ponto de vista do direito é uma forma prática da estrutura organizacional da empresa do ponto de vista do direito, bem como as disposições elementares das operações que envolvem a atividade econômica oriundas das relações de direito empresarial, sendo elas: consumo, civil, trabalho, econômico, penal e falimentar (falência).

As organizações empresariais são dispostas com base no desenvolvimento humano e a gestão alocada em dado momento histórico permitem a racionalidade da responsabilidade da atividade promovida diante a função social

Como toda e qualquer atividade com ou sem fins econômicos, o exercício individual ou organizacional está ligado aos fatores objetivos da responsabilidade civil, sendo que toda e qualquer atividade comporta riscos e não há negócio sem probabilidade de insucesso.

A análise prático-teórica da Teoria do Risco fundamenta o nexo causal do agente em relação dano promovido, haja vista no exercício da atividade empresarial estar aliada ao risco da produção e circulação de bens e serviços diretos e indiretos ligada às dinâmicas do empreendimento, do desenvolvimento e ao proveito lucrativo da atividade. 
A exclusão da verificação de culpa diante a responsabilidade objetiva nos termos do art.927, parágrafo único do Código Civil parece a melhor solução haja vista que a sociedade deve sempre prevalecer frente as ações privadas econômicas, sendo fator principal e não acessório do mercado. Assim, qualquer prejuízo individual e coletivo deve ser devidamente indenizado.

A responsabilidade civil objetiva no exercício da livre iniciativa econômica ligada as organizações empresariais são fundadas em complexidades negociais de direito privado e direito público, do qual nem sempre podem ser atenuadas ou excluídas diante a obrigação indenizatória do dano proveniente no patamar social. O Estado deve ponderar quando das políticas econômicas visam prejudicar as organizações empresárias e, nesse ponto nem sempre a jurisprudência se firma com razoabilidade diante as políticas públicas do mercado junto ao nexo de culpa presumida ao risco provocado.

Por fim, a responsabilidade civil das empresas é um conteúdo a ser melhor desenvolvido e pesquisado. Vale refletir o cenário atual das pequenas organizações empresárias brasileiras que em sua maioria possui um ciclo de vida pequeno, pois o risco da atividade (empreendimento) dependente de planos públicos econômicos não beneficiam a livre iniciativa econômica, como procedimentos burocráticos administrativos, agregados a uma complexidade legislativa e burocrática dos ramos jurídicos que decorrem da função social da empresa (direito do trabalho, tributário, previdenciário, ambiental, consumo, mercantil, civil e mercantil).

\section{REFERÊNCIAS}

AFONSO, Humberto Manoel. A responsabilidade empresarial no código civil. 0 art. 931, seu conteúdo e alcance. Revista Jurídica: órgão nacional da doutrina, jurisprudência, legislação e crítica judiciária, ano 52, n.321, Porto Alegre, jul. 2004.

BARROS, Luiz Sérgio. Livre iniciativa: um caminho para o desenvolvimento. vol.5. - Brasília: Coleção Brasil, 1998.

BRASIL Lei n 10.406, de 10 de janeiro de 2002. Código Civil Brasileiro. Legislação Federal. Disponível em: <http://www.planalto.gov.br/ccivil_03/leis/2002/L10406compilada.htm>. Acesso em: 17 ago.2012.

BRASIL. Constituição (1988). Constituição da República Federativa do Brasil: promulgada em 5 de outubro de 1988. Contém as emendas constitucionais posteriores. Brasília, DF: Senado, 1988. 
BULGARELLI, Waldirio. Direito comercial. 16. Ed.São Paulo: Atlas, 2001. . Sociedades comerciais. 8. Ed. - São Paulo: Atlas, 1999.

CALIXTO, Marcelo Junqueira. A responsabilidade civil do fornecedor de produtos pelos riscos do desenvolvimento. Rio de Janeiro: Renovar, 2004.

CARVALHO, Leonardo Arquimimo de. Manual de direito de concorrência. - São Paulo: IOB Thomson, 2005.

CARVALIERI FILHO, Sérgio. Programa de responsabilidade civil. 7. ed. São Paulo: Atlas, 2007

DINIZ, Maria Helena. Curso de direito civil brasileiro. v.7. São Paulo: Editora Saraiva, 2004.

FAZZIO JÚNIOR, Waldo. Manual de Direito Comercial. 5. ed. São Paulo: Atlas, 2005, p.36.

FERNANDES, Francisco. LUFT, Celso Pedro. GUIMARÃES, F. Marques. Dicionário brasileiro globo. 21. ed. São Paulo: Globo, 1991.

FRAN, Martins. Curso de direito comercial. 27. ed. Rio de Janeiro: Forense, 2001.

HAYEK, Frederick A. Von. La componente moral da la libre entreprise. Disponível em: <http://www.dantou.fr/Economie.html. Acesso em: 15 ago. 2012.

NEGRÃO, Ricardo. Manual de direito comercial e a de empresa. v. 1. 3. ed. São Paulo: Saraiva, 2003.

PACKER, Amilcar Douglas. Direito comercial - origem e evolução. 1. vol. Curitiba: Juruá, 2002.

PEREIRA, Caio Mário da Silva. Responsabilidade Civil. Rio de Janeiro: Forense, 1990.

RIOS, Roger Raupp. Ordem econômica, sociabilidade e os mass media na constituição da república de 1988. Revista Justiça do Direito - UPF, Passo Fundo, v.9, n.9, 1996.

SAKAMOTO, Bernardo Alfredo Mayta. Da ordem astronômica à ordem social: a gravitação e o indivíduo como fundamentos do Mercado. Cascavel: Edunioeste, 2010. p.97.

SALIM, Adib Pereira Netto. A teoria do risco criado e a responsabilidade objetiva do empregador em acidentes de trabalho. Revista do Tribunal Regional do Trabalho $3^{\text {a }}$ Região, Belo Horizonte, v.41, n.71, jan./jun.2005.

SARLET, Ingo Wolfgang. As dimensões da dignidade humana: construindo uma compreensão jurídico-constitucional necessária e possível. In: Dimensões da dignidade: ensaios de Filosofia do Direito e Direito Constitucional. 2. ed. Porto Alegre: Livraria do Advogado, 2009.

SCHIEMANN, Georg; BARTLMAE, Elmar. Sob o domínio de Napoleão - parte 1 [Filme-video]. BIEHOUNEK, Ulrike (Coord.). Life under Napoleon. Alemanha, MDR/WDR/LOOKS Coorporation, 
ISSN 1981-3694

(DOI): $10.5902 / 1981369410856$

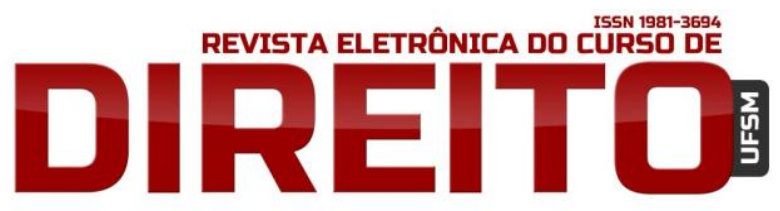

A RESPONSABILIDADE CIVIL NO EXERCÍCIO DA LIVRE INICIATIVA CONSTITUCIONAL NAS ORGANIZAÇÕES EMPRESARIAIS

GIVAGo DIAS MENDONÇA

2006. Web-video, 52:53 min. Som stereo. Disponível em:<

http: / /www.youtube.com/watch?v=BFMngo-dtEk>. Acesso em: 15 ago. 2012.

SMITH, Adam. Riqueza das nações. Vol. 1 e 2. $1^{\text {a }}$ ed. São Paulo: Martin Fontes, 2003.

WOLKOFF, Alexander Porto Marinho. A teoria do risco e a responsabilidade civil objetiva do empreendedor. Disponível em: <

http://www.tjrj.jus.br/c/document_library/get_file?uuid=ae2e5cc8-fa16-4af2-a11f-

c79a97cc881d\&groupld=10136> Acesso em: 16 dez. 201

Recebido em: 01.10.2013

Correções em: 29.12.2013

Aprovado em: 08.03.2014 